\section{O Ensino de História da África: Projetos Institucionais e o Processo de Formação de Professores}

\section{Resumo}

Propomos neste artigo uma reflexão sobre a emergência dos estudos sobre história da África e sua inserção no ensino básico. A experiência vivenciada no PIBID (Programa Institucional de Iniciação à Docência), na Universidade Federal do Amazonas, possibilitou refletir sobre as contribuições e importância da História da África no processo de ensino e aprendizagem de História, e no processo de formação de professores de História.

Palavras-chave: História da África; Educação étnico-racial; Literacia histórica, Consciência histórica.

\section{Abstract:}

In this paper, we propose a reflection on the rising of studies on the African history and its insertion in basic education. The lived experiences in PIBID (Institutional Program of Initiation to Teaching), at the Federal University of Amazonas, started a reflection process around the contribution and the relevance of African History, into the African History teaching and learning process and in the history teacher formation process.

Keywords: History of African; Ethnic-racial Education; Historical Literacy; Historical Awareness.

\section{Introdução}

A constituição e fortalecimento da área de estudos africanos nas universidades brasileiras estão ligados à promulgação da lei $n^{\circ} 10.639$, de janeiro de 2003, que tornou obrigatório os conteúdos de ensino de História da África e da cultura afro-brasileira nos currículos escolares. Contudo, o processo de crescimento e ampliação do debate sobre o ensino de História da África e da educação das relações étnico-raciais se deu de forma diferenciada nas diversas regiões do país.
Patrícia Rodrigues da Silva

Doutora em História. Universidade Federal do Amazonas.

Email: parosilva

@yahoo.com.br

Keith Valéria de Oliveira Barbosa

Doutora em História. Universidade Federal do Amazonas.

Email: keithbarbosa @hotmail.com 
Nesse sentido, cabe direcionar o nosso esforço analítico em torno de alguns cenários amazônicos, observando os desdobramentos, silêncios e percepções dos alunos discentes do curso de licenciatura em História, examinando o desenvolvimento dos conteúdos de ensino de História da África no âmbito do Programa Institucional de Bolsa de Iniciação à Docência (PIBIB) da Universidade Federal do Amazonas. Tal debate justifica-se, considerando que este tempo presente tem constituído de uma enormidade de fatos, eventos, transformações tão rápidas, que acaba por exigir do historiador interessado nas interações entre África e o Brasil um olhar mais atento à História a sua volta.

De acordo com Astrogildo Fernandes da Silva Júnior e José Josberto Montenegro Sousa, a lei $n^{\circ} 10.639 / 2003$ foi fundamental para a "construção de uma educação antirracista por meio do combate às práticas discriminatórias contra negros e seus descendentes no meio escolar e, de forma mais ampla, no contexto educacional brasileiro" (SILVA JÚNIOR; SOUSA, 2016, p. 68). Logo, ao refletirmos sobre o impacto e os desdobramentos da legislação federal na cidade de Manaus, não podemos desvincular a importância do ensino de História para a educação das relações étnico-raciais na capital amazonense.

Walter Benjamin (1987), nos anos de 1940, já asseverava que "a História é objeto de uma construção cujo lugar não é o tempo homogêneo e vazio, mas um tempo saturado de "agoras" (1987, p. 231). Essa perspectiva chama a atenção para a ideia de que a História, menos que narrar fatos estanques e vazios de significação do passado, é plena de sentidos e significados do presente. Dito de outra forma, a História, ainda que trate do passado, o faz impulsionada pelos apelos que o presente impõe ao historiador No que tange ao passado brasileiro, os diversos processos de interações entre o continente africano e o Brasil ainda são pouco discutidos nas salas de aula do norte do país.

É consenso entre os historiadores que o trabalho é ancorado no tempo e que toda interpretação se assenta no presente. Portanto, passados dezessete anos após a Lei 10.639/2003, verificamos avanços no que tange ao ensino de História da África no país. Ao observamos o debate acadêmico histórico no decorrer desse processo, encontramos dois historiadores que formularam perguntas interessantes e que nos ajudam a refletir sobre a importância do ensino de História da África no Brasil.

Em 2003, Anderson Ribeiro Oliva, apresentou a seguinte pergunta no início do seu texto: "Como ensinar o que não se conhece? (OLIVA, 2003, p. 423). Após treze anos da Lei 10.639/2003, Amailton Magno Azevedo formulou a seguinte provocação no título do seu artigo "Qual África ensinar no Brasil? (AZEVEDO, 2016).

Observamos que com a promulgação da Lei 10.639 em 2003, diversos pesquisadores das ciências humanas passaram a denunciar as lacunas, as fragilidades da comunidade acadêmica em formar profissionais competentes para os conteúdos da História da África. Era evidente a falta de profissionais, de material didático especializado, etc.

Após pouco mais de uma década, com o desenvolvimento e consolidação de uma historiografia sobre o ensino de História da África no Brasil, novos questionamentos foram formulados a respeito dos conteúdos, das perspectivas teóricas e metodológicas.

De acordo com Amailton Magno Azevedo, ao problematizar sobre qual África ensinar no Brasil, pretendia:

\footnotetext{
(...)rastrear as questões de ordem teórica de como se inventou a África, bem como, perceber desde os debates em torno dos estudos africanos sob a perspectiva da descolonização, às questões emergentes postas pela crítica pós-colonial, quando novos desafios teóricos se colocam para desconstruir os clichês sobre a África. (AZEVEDO, 2016, p. 235)
}

Superado o desafio em relação ao desconhecimento sobre a África, foi possível elaborar novas propostas sobre como produzir esse conhecimento. Rubia Caroline Janz e Luiz Fernando Cerri (2018), em um artigo sobre os treze anos da 
Lei 10639/2003, defendem que o acesso ao conhecimento sobre a África e a trajetória da cultura afro-brasileira é essencial para superarmos os estereótipos de inferioridade e dominação histórica. Segundo os autores, "As mudanças propostas na lei sustentam-se na mudança da perspectiva do olhar que o ensino de História deu aos negros até então" (JANZ e CERRI, 2018, p. 192.). Tal perspectiva, ao redimensionar a importância do ensino de História da África nos currículos escolares na contemporaneidade, além de contribuir para a superação da agenda colonialista, favorece a educação das relações étnico-raciais.

Logo, nesse tempo presente torna-se essencial refletirmos sobre qual África ensinar no Brasil, direcionando o debate para a desconstrução dos clichês sobre o continente africano, marcada por uma visão racializada e essencializada das populações africanas. Em relação a esse desfazer permanente de estereótipos, o escritor Mia Couto argumenta que, "São dinâmicas próprias e os conflitos particulares que definem identidades plurais, complexas e contraditórias. O rosto do continente só existe em movimento, no conflito entre o retrato e a moldura" (COUTO, 2008, p. 12).

\section{Percursos da História ensinada - Consciência Histórica e Literacia Histórica: O PIBID de História na UFAM}

A última década do século XX foi marcada por mudanças significativas no âmbito do ensino brasileiro de forma geral e, no ensino de História, de forma específica. Fruto de lutas e disputas engendrados ao longo dos anos 1990', os (PCNs) Parâmetros Curriculares Nacionais foram lançados em 1997 consoante a Lei de Diretrizes e Bases de 1996.

1 Sobre esse debate ver o texto: PEIXOTO, M. do R. da C. Ensino como pesquisa: um novo olhar sobre a história no ensino fundamental como e por que aprender/ensinar história. História e Perspectivas, Uberlândia (53): 37-70, jan./jun. 2015. Disponível em: <https://bit.ly/2WGqlHG>. Acesso em: 15/02/2020.
Entre polêmicas, retrocessos e avanços naquele documento, destacamos a importante conquista da abordagem da História do Tempo Presente. De fato, àquela altura, os PCNs de História advogavam que os conteúdos de História deveriam abarcar uma "perspectiva de questionamentos da realidade organizada no presente" (BRASIL, 1997, p. 54).

Consolidava-se assim, uma perspectiva de História que partia das questões do presente para problematizar e historicizar os processos vivenciados pelos alunos na educação básica, possibilitando, portanto, a construção de um ensino de História concretamente significativo para a sociedade.

Entretanto, cabe elucidar ainda, que entre avanços e retrocessos, encontra-se atualmente, em vias de implementação, a BNCC (Base Nacional Comum Curricular)2 para a Educação Básica (ensino fundamental e médio). Destaca-se aqui o Ensino Médio, documento esse que tem gerado grandes críticas e controvérsias entre especialistas de diversas áreas, dentre elas e não sem razão, a dos professores historiadores.

A Medida Provisória n. 746 de 2016 sancionada como Lei 13.415, em 16 de fevereiro de 2017, representou um duro golpe na área de História. Dentre os muitos elementos controversos e passíveis de críticas, citamos o art. $3^{\circ}$ que estabelece:

\section{$\S 3^{\circ} \bigcirc$ ensino da língua portuguesa e da matemática será obrigatório nos três anos do ensino médio, assegurada às co- munidades indígenas, também, a utiliza- cão das respectivas línguas maternas. \\ $\S 4^{\circ}$ Os currículos do ensino médio inclui- rão, obrigatoriamente, o estudo da língua inglesa (...).}

Ao estabelecer apenas três disciplinas como obrigatórias no decurso de todo ensino médio,

2 BRASIL. Base Nacional Comum Curricular. Brasília: MEC, 2017. Disponivel em: < https://bit.ly/2WGM4PE>.

3 BRASIL. LEI № 13.415, DE 16 DE FEVEREIRO DE 2017. Poder Executivo, Brasília/DF. Disponível em: <https://bit.ly/2WGSazn> 
a lei abre possibilidades para o questionamento acerca da necessidade, importância, sentido e eficácia de um amplo leque de conhecimentos, especialmente na área das ciências humanas.

Nessa perspectiva, como reafirmar os sentidos e a importância de se estudar História? Como legitimar a disciplina no espaço de formacão de professores? Como nós, que trabalhamos com a formação de professores de História, reafirmamos e podemos contribuir na construção da identidade do profissional de História?

Outro aspecto importante a se pensar é que ainda se fazem presentes, se não nos nossos departamentos, mas nas escolas de ensino básico, o perigo da História e da memória única monumentalizada, das verdades absolutizadas e inquestionadas e como nós, professores e alunos dos cursos de História, podemos lidar com isso e contribuir para construção de um ensino de História plural, significativo para a realidade plural de nossos alunos. E como esse ensino pode contribuir na perspectiva tão almejada de formar cidadãos críticos de sua própria realidade, desnaturalizando-a e a percebendo como construção cultural e, por isso mesmo, passivel de transformações.

Todas essas questões permeiam tanto o complexo processo da formação do professor de História como também, e fundamentalmente, os conteúdos e os sentidos de ensinar a disciplina. Nessa perspectiva, compreendo que vida, trabalho e identidade se formam e se conformam mutuamente e a História do Tempo Presente tem um importante papel nesse processo. Pensar essas questões nos leva a refletir necessariamente sobre a função do ensino de História. Por que ensinamos História da África na escola? O que é e como ensinamos essa História?

Podemos considerar que o ensino de História esteja relacionado fundamentalmente à formação da consciência histórica, conforme Jörn Rüsen a define como o "processo mental da consciência histórica pode ser rapidamente descrito como o significar da experiência do tempo interpretando o passado, de modo a compreender o presente e antecipar o futuro" (RÜSEN, 2009, p. 68).
A consciência histórica, ainda segundo Rüsen, envolveria alguns procedimentos mentais, entre os quais, destaco a orientação da ação humana pela interpretação histórica e a motivação para a ação que uma orientação oferece. Se a função do ensino de História é formar uma consciência histórica, poderíamos a partir daqui formular outra pergunta: qual seria a função da consciência histórica? Suponho que a principal função dela no ensino da História é fornecer ao educando as ferramentas que the permitam compreender o passado como uma construção histórica apta a orientá-lo no tempo.

Outro conceito importante nessa perspectiva é "literacia histórica". Elaborado por Peter Lee, refere-se à habilidade para movimentar conceitos sobre História quando se interpreta dada realidade. Mais do que isso - uma competência de leitura e compreensão linguística - a "literacia histórica" está intimamente ligada à Educação Histórica, como indispensável para que ocorra o desenvolvimento da Consciência Histórica (BARCA, 2006; SCHIMIDT, 2009).

Peter Lee utiliza o termo "literacy", como "alfabetização", e a palavra "literacia" vem sendo utilizada mais especificamente pelos pesquisadores ligados ao campo da Educação Histórica. Neste sentido, como explicitado pelo próprio autor, a "literacia histórica" baseia-se nos estudos de Jörn Rüsen sobre a Consciência Histórica, e em suas considerações sobre a função do conhecimento histórico para a "vida prática" enquanto orientador da experiência humana no tempo (LEE, 2006, p. 134).

Jörn Rüsen (2011) sustenta que:

A consciência histórica serve como um elemento de orientação chave, dando à vida prática um marco e uma matriz temporais, uma concepção do 'curso de tempo' que flui através dos assuntos mundanos da vida diária. Essa concepção funciona como um elemento nas intenções que guiam a atividade humana, nosso 'curso de ação'. A consciência histórica evoca o passado como um espelho da experiência na qual se reflete a vida presente, e suas características temporais são, do mesmo modo, reveladas. (RÜSEN, 2011, p. 58) 
A consciência histórica é, portanto, o que nos permite, enquanto seres humanos, atribuir sentido e significado ao nosso passado, o qual se reflete no presente, influindo em nossas escolhas, em nossa experiência e, de modo geral, perpassa a nossa ação naquilo que ele chama de "vida prática". A forma como relacionamos a experiência passada, a relação que temos com o presente e o futuro teriam estreita ligação com o tipo de consciência histórica ${ }^{4}$.

Neste sentido, podemos dizer que a narrativa ganha destaque, pois é por meio dela que se tem acesso à consciência histórica do sujeito:

Essa competência pode se definir como a habilidade da consciência humana para levar a cabo procedimentos que dão sentido ao passado, fazendo efetiva uma orientação temporal na vida prática presente por meio da recordação da realidade passada. Esta competência geral relativa a 'dar sentido ao passado' pode ser definida em termos dos três elementos que constituem juntos uma narração histórica: forma, conteúdo e função. Em relação ao conteúdo, pode-se falar de 'competência para a experiência histórica'; em relação à forma, de 'competência para a interpretação histórica'; e em relação à função, de 'competência para a orientação histórica'. (RÜSEN, 2011 p. 59)

A experiência, a interpretação e a orientação buscam respaldo na consciência histórica do indivíduo. A experiência envolve a capacidade de aprender a olhar o passado diferenciando-o do presente. A interpretação possibilita atribuir significado à experiência e, a orientação, supõe uma capacidade para se utilizar do todo temporal, quando da orientação para vida.

Para Rüsen, a aprendizagem histórica deve ser direcionada no sentido de levar o educando a desenvolver uma consciência histórica onto-

4 Para uma discussão mais aprofundada ver: RÜSEN, Jörn. O desenvolvimento da competência narrativa na aprendizagem histórica: uma hipótese ontogenética relativa à consciência moral. In: SCHIMIDT, M. A.; BARCA, I. e MARTINS, E. R. (Orgs.). Jörn Rüsen e o Ensino de História. Curitiba: Editora UFPR, 2011. genética, em que o sentido do passado seria, propriamente, a mudança e o argumento de que os tempos mudam. Neste tipo de consciência, a memória histórica representa a "experiência da realidade passada como acontecimentos mutáveis", e "vê a vida social em toda a abundante complexidade de sua temporalidade absoluta" (RÜSEN, 2011 p. 59).

Para o autor, na consciência ontogenética:

futuro supera, excede efetivamente o passado em seu direito sobre o presente, um presente conceituado como uma intersecção, um nó intensamente temporal, uma transição dinâmica, esta é a forma refinada de uma espécie de pensamento histórico moderno marcado pela categoria de progresso, ainda que tenha sido arrojado por uma dúvida radical pelas intimações da pós-modernidade, pensadas por certo segmento da elite intelectual contemporânea. (RÜSEN, 2011 p. 69)

Para Lee (2006), a aprendizagem em história também implica em uma mudança estrutural nesta consciência e, como condição para esta aprendizagem. Ele mostra a importância de apreender as ideias sobre história que trazem os estudantes, mas não só isso: é importante entender com clareza sobre qual, ou quais, os conhecimentos que queremos que o aluno tenha ao final do curso na disciplina história. Assim, já definindo alguns pressupostos para a literacia histórica, ele considera:

Uma primeira exigência da literacia histórica é que os alunos entendam algo do que seja história, como um 'compromisso de indagação' com suas próprias marcas de identificação, algumas ideias características organizadas e um vocabulário de expressões ao qual tenha sido dado significado especializado: 'passado', 'acontecimento', 'situação', 'evento', 'causa', 'mudanca' e assim por diante. (LEE, 2006, p. 136)

Para instigar o aluno a raciocinar historicamente, é necessária uma postura questionadora acerca do passado, em que tais conceitos 
apontados pelo autor - acontecimento, evento, causa, etc. - são importantes para a construcão de um conhecimento histórico. Lee aponta que, para isso, os alunos deveriam entender: o conceito de evidência como importante para a possibilidade de um conhecimento histórico; o fato de as explicações históricas serem contingentes e condicionais, ou seja, reconstroem valores, situações e intenções relevantes; a de que as explicações em história não são cópias fiéis do passado, mas, no mínimo, questões relativas ao âmbito do documento em questão (LEE, 2006, p. 136).

Assim, mais importante do que apreender os fatos históricos e conceitos históricos, é atribuir significado ao passado, tendo em vista que esta atribuição de significado ao passado é o próprio conhecimento sobre ele, na medida em que é impossivel apreendê-lo em sua totalidade e que as explicações sobre ele são relativas, produzidas sob uma série de fatores que influenciam nas relações de poder que envolvem a produção do conhecimento histórico.

A consciência histórica tem, portanto, uma importantíssima função cultural, que é a de contribuir para a formação da identidade. Assim, ela é expressiva no processo de formação da identidade e é capaz de orientar o indivíduo e a sociedade (esta quando se considera uma consciência histórica coletiva) no tempo.

Refletir sobre a sala de aula e nosso papel de professores como colaboradores/fomentadores da construção dessa consciência histórica nos instiga a pensar por quais caminhos forma-se essa consciência histórica na sala aula e mais, qual o tipo de consciência histórica forma-se. São considerações que estão coladas e, por serem bastante amplas, faremos a seu respeito apenas alguns apontamentos gerais que consideremos pertinentes frente à nossa problemática.

Ao fazer essa reflexão no âmbito do PIBID (Programa Institucional de Bolsas de Iniciação à Docência) do qual participamos no edital 20132018, compreendemos que era necessário partir de um olhar contextualizado da realidade dos alunos da escola onde desenvolvíamos o projeto.

\section{Caminhos Percorridos no PIBID História-UFAM}

Pensar historicamente o tempo presente daqueles sujeitos (alunos e comunidade escolar) se mostrou, portanto, fundamental para um ensino de História que fizesse mais sentido, que fosse mais significativo para aqueles alunos e concomitante a isso, que pudesse fomentar nos bolsistas (futuros professores) a construção de sua identidade docente.

Foi nesse contexto que a temática da educação para as relações étnico-raciais foi compreendida como essencial. Embora não fosse o foco do subprojeto de História, estava claro que ela perpassaria fundamentalmente pelas ações que pretendíamos desenvolver.

As discussões apresentadas anteriormente foram realizadas no âmbito do PIBID e compreendemos que as ações deveriam, portanto, partir da realidade e das questões colocadas na/ pela escola, pelos alunos na sala de aula. Nesse contexto, emerge a ideia de realizar a Feira da Consciência Negra na Escola Municipal Carolina Perolina Raimunda Almeida, escola situada no bairro São José, na Zona Leste de Manaus.

Compreendemos que a relevância desse tema passava pela permanência das desigualdades entre negros e não negros na escola em que atuávamos e como isso estava evidenciado no tratamento recebido pelos alunos das diversas autoridades da escola e ainda frente aos questionamentos dos próprios alunos. Importa ressaltar que nossa consciência histórica não se forma apenas com as aulas de História, nossas aulas concorrem com espaços não formais, mídia, história oficial.

Era importante também pelo fato de a temática ser questionada em sua importância e mais que questionada pela resistência sofrida pelo sistema educacional como um todo, mas também e, principalmente, a ponta do processo, pois muitos professores ainda sentem dificuldades em trabalhar essas temáticas por conta de um preconceito racial que insiste em permanecer ${ }^{5}$.

5 Em 2012 foi emblemático o caso de um grupo de alu- 
Cabe lembrar ainda que a Constituição Federal de 1988 coloca como objetivo superar essa desigualdade, sendo assim, temos que perceber e incrivelmente convencer muitos pais e mesmo professores, gestores, de que essa demanda é suprarracial e suprapartidária e que está no cerne de nossa Constituição.

A partir dessas considerações, foi proposta uma série de atividades com os alunos dos oitavos anos. Uma das atividades bastante frutuosa foi a roda de conversas, em que os discentes se organizavam em grupos para debater sobre suas ideias e conhecimentos sobre racismo, preconceito, injúria e sobre a situação dos negros no Amazonas. Os bolsistas se propunham a ouvi-los e mediar as conversas.

Após as rodas de conversas, alguns conceitos emergiram como problemas. Assim, os bolsistas pibidianos realizaram oficinas com os discentes, a fim de possibilitar a reflexão sobre a importância de valorizar a diversidade, os significados de preconceito, racismo, bem como oficinas culturais nas quais os alunos puderam perceber os significados políticos da cultura afro-brasileira. Nesse aspecto, podemos destacar a oficina de turbantes.

Pensamos as oficinas culturais como espaço de aprendizagem e reflexão que não pautassem apenas o diferente ou o exótico, mas que possibilitasse aos alunos que olhassem para si e pensassem na importância da representatividade, nas implicações materiais de atitudes discriminatórias e racistas. Tudo isso por meio de aulas programadas, filmes que valorizassem a cultura, palestras e manifestações artísticas considerando não apenas a estética pela estética, mas trazendo em seu bojo os sentidos e significados políticos da capoeira, dos turbantes, da alimentação da linguagem, dos diversos ritmos e músicas.

O trabalho teve seu ponto culminante na realização da feira, propriamente dita. A divulgação

nos de uma escola estadual em Manaus, apoiados por pais e pastores que se recusaram a realizar atividades alusivas ao dia da consciência negra, Casa Grande e Senzala. Conferir reportagem: <https://bit.ly/2Bo7KZy>. foi realizada de sala em sala pela professora de História e pelos bolsistas pibidianos, que aproveitaram o mote dos turbantes para despertarem uma reflexão nas diversas turmas da escola.

A Feira da Consciência Negra, realizada em 20 de novembro de 2017, nas salas dos oitavos anos da Escola Municipal Carolina Perolina Raimunda Almeida, foi importante porque revelou o resultado de um processo desenvolvido a partir e com os alunos. Suas conclusões e avaliações apareceram nas exposições orais realizadas por eles com entusiasmo, pois, fruto de suas pesquisas, tinham segurança para expor e falar.

Compreendemos que seja muito necessário fazer um balanço da eficácia dessas ações tanto no âmbito das ações nas escolas quanto no processo de formação de professores e suas identidades. Embora não tenhamos feito, ainda, uma avaliação quantitativa sobre essas ações, as avaliações subjetivas nos dão conta de importantes avanços sim. São muitos depoimentos dos alunos, e dos bolsistas de iniciação à docência que dão conta de outros olhares, outras formas de ver sua própria realidade e a realidade do outro.

Este contanto com a escola, é essencial para pôr em prática todos os conceitos que vemos em aulas, é a forma mais concreta de viver com a realidade da docência, e acrescenta muito, pois cada aula é uma nova aprendizagem, uma nova experiência, para que no futuro possamos ter a base do que é ser um professor regente. Bruno Venâncio Peragine - Outubro 2017.

É gratificante enxergar o empenho dos alunos pondo as expectativas a funcionar e, por mais que eu tenha consciência disso, que o fazer do professor precisa se dar junto com o aluno. Roberval Nascimento da Silva Junior - Novembro 2017.

Foi bastante produtivo para os alunos e os pibidianos discutirem africanidades dentro da escola. $\bigcirc$ evento que fizemos levantou questionamentos e resistências por parte de certos professores, mas o 
nosso compromisso com os estudantes se fez. (...) (Participar do PIBID) foi um salto gigantesco para a minha formação como professor. Pude perceber ao realizar os estágios supervisionados, que o PIBID me proporcionou segurança e uma preparacão maior como professor dentro da sala de aula. - Wenderson - Maio 2018.

Ao falar sobre sua experiência no PIBID, os futuros docentes nos apontam para a importância do Programa no seu processo de formação e mais que isso, nos mostra que um ensino de História realmente significativo e com sentido pode ser construído na medida em que partimos de olhares do presente, dos problemas que estão localizados no presente dos alunos e assim buscamos reflexões que nos permitem construir outros olhares, outras narrativas sobre nosso processo histórico.

A reflexão sobre a construção da identidade na formação de professores de História está intrinsecamente vinculada com a valorização do ensino de História. E esse ensino se mostra socialmente válido e importante na medida em que parte de reflexões próximas à realidade dos alunos. Nesse sentido, a História do Tempo Presente tem muito a contribuir com a construção de um ensino de História que realmente colabore com a formação de um cidadão crítico e atuante no seu meio social.

\section{Considerações Finais}

A História do Tempo Presente nas escolas de ensino básico possibilita a percepção de que as narrativas únicas são sempre enganadoras. Nesta perspectiva, podemos tomar a fala da escritora nigeriana, Chimananda Adchie, sobre o que gosta de chamar de "o perigo da história única". Ela conta de sua experiência de leitura desde a infância. Quando jovem também começou a escrever e foi influenciada pelos livros infantis que lia. A escritora argumenta que todos os seus personagens eram brancos e de olhos azuis, brincavam na neve, comiam maçãs, etc. Isso demonstra, segundo a autora, o quão vulneráveis somos face a uma história.
Como eu só tinha lido livros nos quais os personagens eram estrangeiros, tinha ficado convencida de que os livros, por sua própria natureza, precisavam ter estrangeiros e ser sobre coisas com as quais eu não podia me identificar. Mas tudo mudou quando descobri os livros africanos (...). Percebi que pessoas como eu, meninas com pele cor de chocolate, cujo cabelo crespo não formava um rabo de cavalo, também podiam existir na literatura. (ADICHIE, 2019, p. 13 e 14)

Daí a importância de se apresentar as múltiplas histórias e como a representatividade é importante na formação de crianças e jovens. A construção da identidade de professores de História deve dialogar e apresentar a diversidade em seu sentido político. Logo, em nosso país, a história da África se faz fundamental.

Importa ressaltar ainda que a ampliação do debate sobre o ensino de história da África no Brasil contribui tanto para uma reflexão sobre os atuais problemas sociais do nosso país, quanto para a possibilidade de rompermos com a perspectiva colonialista nos currículos escolares. Deste modo, é possível repensarmos os conteúdos, a formação do espaço escolar e o próprio currículo no que tange ao ensino de história da África, da educação, das relações étnico-raciais.

\section{Referências}

ADICHIE, C. N. O perigo de uma história única. 1. ed. São Paulo: Companhia das Letras. 2019.

AZEVEDO, A. M. Qual África ensinar no Brasil? Tendências e perspectivas. Projeto História, São Paulo, n. 56, pp. 233-255, Mai.-Ago. 2016. Disponível em: <https://revistas.pucsp.br/index.php/ revph/article/view/6072>. Acesso em: 06/05/20.

BENJAMIN, W. Teses sobre História. In: Obras escolhidas. Vol. 1. Magia e técnica, arte e política. Ensaios sobre literatura e história da cultura. Prefácio de Jeanne Marie Gagnebin. São Paulo: Brasiliense, 1987, p. 222-232.

BRASIL. Ministério da Educação e Cultura. Secretaria de Educação Fundamental. Parâmetros 
curriculares nacionais: terceiro e quarto ciclos do ensino fundamental: história. Brasília, 1997.

BRASIL. Lei $n^{\circ}$ 13.415, de 16 de fevereiro de 2017. Poder Executivo, Brasília/DF. Disponível em: <http://www.planalto.gov.br/ccivil_03/_ato20152018/2017/lei/L13415.htm>. Acesso em: 15/02/20.

COUTO, M. Prefácio. In: HERNANDEZ, L. L. A África na sala de aula: visita à história contemporânea. São Paulo: Selo Negro, 2008.

JANZ, R. C.; CERRI. L. F. Treze anos após a Lei $n^{\circ}$ 10.639/03: o que os estudantes sabem sobre a história da África? (Ponta Grossa, 2015). Afro-Ásia, 57 (2018), 187-211. Disponível em: <https:// portalseer.ufba.br/index.php/afroasia/article/ view/21562>. Acesso em: 06/05/20.

LEE, P. Em direção a um conceito de literacia histórica. Curitiba: Editora UFPR, 2006. p. 131-150.

OLIVA, A. R. A História da África nos bancos escolares. Representações e imprecisões na literatura didática. Estudos Afro-Asiáticos, ano 25, n³, 2003, pp. 421-461.Disponível em: <https:// www.scielo.br/pdf/eaa/v25n3/a03v25n3.pdf>. Acesso em: 06/05/20.

PEIXOTO. M. do R. da C. Ensino como pesquisa: um novo olhar sobre a história no ensino fundamental como e por que aprender/ensinar história. História e Perspectivas, Uberlândia (53): 37-70, jan./jun. 2015. Disponível em: <http:// www.seer.ufu.br/index.php/historiaperspectivas/ article/view/32765>. Acesso em: 06/05/20.

RÜSEN, J. O desenvolvimento da competência narrativa na aprendizagem histórica: uma hipótese ontogenética relativa à consciência moral. In: SCHIMIDT, M. A; BARCA, I. e MARTINS, E. R. (Orgs.) Jörn Rüsen e o ensino de História. Curitiba. Editora UFPR, 2011.

SCHIMIDT, M. A. Literacia histórica, um desafio para o ensino de história no século XXI. História \& Ensino, Londrina, v.15 p. 09-22. Ago 2009.

;BARCA,I. Apresentação. In: SCHMIDT; M. A.; BARCA, I. Aprender história: perspectivas da educação histórica. Ijuí: Ed. Unijuí, 2009. p. 11-19.
SILVA JÚNIOR, A. F. da; SOUSA, J. J. M. O ensino das relações étnico-raciais: diálogos com os estudos descolonais. Revista Grifos - $n^{\circ} 41, p$. 57-80. 2016. Disponível em: < https://bell.unochapeco.edu.br/revistas/index.php/grifos/article/ view/3659>. Acesso em: 06/05/20.

\section{Depoimentos}

1 - PERAGINE, B. V. Entrevista concedida à Patrícia Rodrigues da Silva e Keith Valéria de Oliveira Barbosa. Amazonas, 2018. Acadêmico do curso de História - UFAM e bolsista PIBID.

2 - JUNIOR, R. N. da S. Entrevista concedida à Patrícia Rodrigues da Silva e Keith Valéria de Oliveira Barbosa. Amazonas, 2018. Acadêmico do curso de História - UFAM e bolsista PIBID.

3 - LIMA, W. M. de L. Entrevista concedida à Patrícia Rodrigues da Silva e Keith Valéria de Oliveira Barbosa. Amazonas, 2018. Acadêmico do curso de História - UFAM e bolsista PIBID 
